\title{
Single-port laparoscopic myomectomy in the virgin womb - a retrospective analysis of 31 consecutive cases
}

\author{
Feng-Hsiang Tang ${ }^{1,2,3}$ \\ 'Department of Obstetrics and Gynecology, Kaohsiung Medical University Hospital, Kaohsiung 807378, Taiwan. \\ 2Department of Obstetrics and Gynecology, Kaohsiung Municipal Ta-Tung Hospital, Kaohsiung 801735, Taiwan. \\ ${ }^{3}$ Graduate Institute of Clinical Medicine, Kaohsiung Medical University, Kaohsiung 807378, Taiwan.
}

Correspondence to: Dr. Feng-Hsiang Tang, Department of Obstetrics and Gynecology, Kaohsiung Municipal Ta-Tung Hospital, No.68, Zhonghua 3rd Rd., Qianjin Dist., Kaohsiung 801735, Taiwan. E-mail: tangfs88@gmail.com How to cite this article: Tang FH. Single-port laparoscopic myomectomy in the virgin womb - a retrospective analysis of 31
consecutive cases. Mini-invasive Surg 2020;4:24. http://dx.doi.org/10.20517/2574-1225.2019.60

Received: 17 Dec 2019 First Decision: 17 Feb 2020 Revised: 7 Mar 2020 Accepted: 10 Mar 2020 Published: 17 Apr 2020

Science Editor: Wei-Min Liu Copy Editor: Jing-Wen Zhang Production Editor: Jing Yu

\begin{abstract}
Aim: We aimed to evaluate the feasibility of single-port laparoscopic myomectomy in the virgin womb.
\end{abstract}

Methods: A retrospective chart review of 31 consecutive cases between November 2017 and October 2019 performed by a single surgeon was performed.

Results: The mean age of patient was $50.10 \pm 7.79$ years old. The mean BMI was $23.55 \pm 4.36 \mathrm{~kg} / \mathrm{m}^{2}$. The mean number of myoma in single patient was $3.84 \pm 2.45$ pieces. The mean maximum diameter of myoma in single patient was $11.24 \pm 3.27 \mathrm{~cm}$. The mean operation time was $182.32 \pm 52.39 \mathrm{~min}$. The mean blood loss was $231.77 \pm$ $238.90 \mathrm{~mL}$. The Visual Analogue Score (VAS) of pain when immediately arriving at the ward after operation was $2.32 \pm 1.60$. The VAS after $24 \mathrm{~h}$ dropped to $1.23 \pm 1.43$. In total, 119 myomas were removed in our study. There were 15 (48.4\%) women with more than four myomas. Fifteen (48.4\%) women had more than two myomas that were $>5 \mathrm{~cm}$. There were $58(48.74 \%)$ intramural myomas, with mean diameter of $6.72 \pm 4.41 \mathrm{~cm}$. Fifty-two (43.70\%) subserous type myoma were removed with mean diameter $2.58 \pm 3.35 \mathrm{~cm}$. Posterior myoma accounted for five (4.20\%) pieces with mean diameter of $9.30 \pm 4.49 \mathrm{~cm}$. The broad ligament type myoma accounted for four pieces (3.36\%), and the mean diameter was $3.74 \pm 1.87 \mathrm{~cm}$. There were $51(42.9 \%)$ myomas $>5 \mathrm{~cm}$ in diameter. Among the different types of myoma, there were $36(62.1 \%)$ intramural type and $6(11.5 \%)$ subserous type, and all posterior and broad ligament type were $>5 \mathrm{~cm}$ in diameter. The blood loss and operation time showed no relationship to

\footnotetext{
(@) $(0$

(C) The Author(s) 2020. Open Access This article is licensed under a Creative Commons Attribution 4.0 International License (https://creativecommons.org/licenses/by/4.0/), which permits unrestricted use, sharing, adaptation, distribution and reproduction in any medium or format, for any purpose, even commercially, as long as you give appropriate credit to the original author(s) and the source, provide a link to the Creative Commons license, and indicate if changes were made.
}

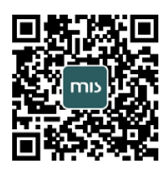


myoma number. There were differences in blood loss $(P=0.0359)$ and operation time $(P=0.0537)$ based on the maximum diameter of myoma. No learning curve was noted in the cumulative sum control chart analysis of the 31 consecutive cases.

Conclusion: In our 31 consecutive cases, the operation time, blood loss, and postoperative VAS score were all comparable to the previously published literature for single-port laparoscopic myomectomy. It is feasible for virgin women with symptomatic myoma to receive single-port laparoscopic myomectomy.

Keywords: Single-port laparoscopy, myoma uteri, virgin

\section{INTRODUCTION}

Myoma uteri, a monoclonal smooth muscle cell tumor, is the most common benign gynecologic tumor in women in childbearing age. Its prevalence varies from $4.5 \%$ to $68.6 \%$ in different studies ${ }^{[1]}$ and tends to increase with age ${ }^{[2]}$. The self-reported prevalence of myoma uteri is $1.8 \%$ in 20 -29-year-old women, but it increases to $7.0 \%$ and $14.1 \%$ in the $30-39$ - and $40-49$-year-old groups, respectively ${ }^{[2]}$.

The symptoms of myoma uteri are annoying and negatively impact the quality of life. Over one third of patients report heavy menstrual bleeding, prolonged duration of menstrual bleeding, and bleeding between periods ${ }^{[2]}$. Moreover, over $50 \%$ of women with myoma uteri report having pain and abdominal cramps during periods, nearly one third report pressure on bladder or inside the abdomen, and nearly $25 \%$ feel pain during sexual intercourse ${ }^{[2]}$. When asked about their symptoms in the last 12 months, over half (50.6\%) of women with myoma uteri reported a negative impact on their daily life ${ }^{[2]}$. Moreover, women with myoma uteri have significantly higher frequency of genitourinary symptoms including stress urinary incontinence, mixed urinary incontinence, urgency, daytime frequency, and dyspareunia ${ }^{[3]}$.

Women with myoma uteri can only receive observation when there are no symptoms. Symptomatic myoma needs either medical or surgical treatment. Medical treatment of myoma uteri includes levonorgestrel intrauterine system, tranexamic acid, non-steroid anti-inflammatory drugs, contraceptive pills, and oral or injected progestogens ${ }^{[4]}$. These treatments can decrease menstrual blood flow or relieve pain, but are not effective in decreasing the size of the myoma. Gonadotropin releasing hormone analogs can effectively decrease myoma size and uterine volume ${ }^{[5]}$. However, the side effects preclude its long-term use. Ulipristal acetate is a selective progesterone receptor modulator that exhibits direct tissue-specific partial progesterone antagonist effects. It is an effective option for both preoperative and intermittent treatment of moderate to severe, symptomatic uterine fibroids in women of reproductive age ${ }^{[6]}$. However, the long-term effect is still not known, and in rare case it can cause severe liver damage ${ }^{[4]}$.

Surgery is a definite treatment for symptomatic myomas, especially for large ones. The bulky effect usually cannot regress quickly enough using non-surgical methods. Hysterectomy is performed if the patient does not want to preserve her uterus. Myomectomy is an alternative method if the patient chooses to preserve her uterus or the woman has not yet completed her childbearing. With the progression of minimally invasive surgery, many surgeons who are familiar with laparoscopic surgery will choose to perform laparoscopic myomectomy in those patients. Single-port laparoscopic myomectomy is more technically difficult but has comparable surgical outcomes ${ }^{[7]}$ to conventional laparoscopic myomectomy, with the benefit of good cosmetic results ${ }^{[8]}$. In this study, we retrospectively analyzed the surgical outcomes of 31 women who had had no sexual experience with symptomatic myomas receiving single-port laparoscopic myomectomy without using uterine manipulator to preserve their virginity in our hospital performed by single surgeon. 


\section{METHODS}

\section{Study design}

This was a retrospective chart review of consecutive 31 women without sexual experience who presented with symptomatic uterine myomas and received single-port laparoscopic myomectomy without using uterine manipulator between November 2017 and October 2019. The hospital setting is a regional teaching hospital (Kaohsiung Municipal Ta-Tung Hospital) but all staff are also members of a medical center (Kaohsiung Medical University Hospital) in Kaohsiung, Taiwan. All surgeries were done by the same gynecologist who is experienced in minimally invasive gynecologic surgery. The inclusion criteria were women with myoma uteri and symptoms such as menometrorrhagia, which causes anemia (Hemoglobin $<11 \mathrm{~g} / \mathrm{dL}$ ), or bulky effect, which cause bearing down sensation, frequency, tenesmus, back soreness, or a palpable pelvic/abdominal mass. The exclusion criteria were as follows: (1) malignancy could not be ruled out by image study; (2) patient was found to have severe adhesion or endometriosis requiring combined major operation at the same time; and (3) patient presented with complex medical condition before operation that required combined care by physician specialists. The largest diameter of myoma was recorded by image study (trans-abdominal ultrasound, abdominal CT, or pelvic MRI). The position and number of myoma was recorded during the operation. The operation time and blood loss were recorded by circulating nurse. The postoperative pain was recorded by charting nurse at bedside immediately when the patient arrived at the ward after operation and $24 \mathrm{~h}$ later. The pain score was measured by the Visual Analogue Scale. Postoperative fever over $38{ }^{\circ} \mathrm{C}$ and prolonged for $48 \mathrm{~h}$ was recorded as a complication. Other perioperative complications within 30 days were recorded. Patients were discharged from the hospital after well tolerating oral intake, successful ambulation, and absence of postoperative fever. All patients were scheduled for follow-up examinations at one week and one month after discharge.

\section{Operation procedure}

The patient is in the supine position. General anesthesia is selected and tracheal intubation is performed to maintain the airway. A single dose of cefazolin $(1 \mathrm{~g})$ is given by intravenous bolus method before operation. The dose is doubled if the patient's body weight is over $80 \mathrm{~kg}$. A Foley catheter is inserted after anesthesia for bladder emptying. We do not use uterine manipulator in these women to preserve their virginity. A $1.5-\mathrm{cm}$ vertical incision is done at umbilicus after sterile preparing and draping of abdomen and within 30 min of intravenous bolus antibiotics. A multi-instrument laparoscopic port (LagiPort ${ }^{\mathrm{TM}} \mathrm{Kit}$, Lagis, Taichung, Taiwan) is inserted through the umbilical incision and properly positioned. We insert a 10-mm telescope to view the pelvic cavity. The circulating nurse records the number and position of myomas. Before uterine incision is performed, diluted vasopressin (1:200 with normal saline) is injected around myomas until bleaching change is seen. We use cold knife scissors to cut the uterine surface until the body of the myoma is reached. An electrothermal bipolar tissue sealing system (LigaSure ${ }^{\mathrm{TM}}$, Medtronic Parkway, MN, USA) is used to control bleeding if necessary. After enough of the myoma body is revealed, a laparoscopic myoma screw is screwed into the myoma body for traction and direction. Then, further dissection of the myoma can be done step by step. After the myoma is removed from the uterine body, we use barbed suture to close the uterine wall defect for at least two layers in intramural type myoma. For superficial subserous myoma or broad ligament myoma, one-layered barbed suture is used if sufficient. After all uterine incisions are sutured, we apply fibrin sealant (Tisseel, Baxter AG, Vienna, Austria) on the suture surface to improve healing and decrease oozing. Large myomas are removed from the umbilical incision by cold knife morcellation. A multi-instrument laparoscopic port is placed again to check for bleeding under telescope. Then, $800 \mathrm{~mL}$ of $4 \%$ Icodextrin solution (Adept, Baxter AG, Vienna, Austria) are infused into the pelvic cavity after clearing blood clot to prevent adhesion. The umbilical incision is sutured layer by layer. All the apparatuses used in our surgery are conventional laparoscopic instruments; no articulated instruments were used in our study. 
Table 1. The demographic data of patient in chronological series

\begin{tabular}{|c|c|c|c|c|c|c|c|c|}
\hline & Age & BMI $\left(\mathrm{kg} / \mathrm{m}^{2}\right)$ & $\begin{array}{c}\text { Number of } \\
\text { myoma }\end{array}$ & $\begin{array}{c}\text { Max diameter of } \\
\text { myoma }(\mathrm{cm})\end{array}$ & $\begin{array}{l}\text { Operation } \\
\text { time (min) }\end{array}$ & Blood loss (mL) & VAS score $1^{\star}$ & VAS score $2^{\star \star}$ \\
\hline 1 & 62 & 19.97 & 4 & 15 & 160 & 20 & 0 & 0 \\
\hline 2 & 61 & 18.44 & 6 & 12 & 225 & 250 & 6 & 3 \\
\hline 3 & 63 & 23.71 & 1 & 16 & 284 & 400 & 0 & 0 \\
\hline 4 & 60 & 28.93 & 1 & 14 & 210 & 1000 & 0 & 3 \\
\hline 5 & 59 & 19.94 & 3 & 14 & 195 & 150 & 4 & 2 \\
\hline 6 & 58 & 32.18 & 3 & 9 & 165 & 400 & 1 & 0 \\
\hline 7 & 57 & 26.00 & 8 & 14 & 290 & 300 & 0 & 2 \\
\hline 8 & 56 & 19.96 & 3 & 9 & 160 & 100 & 3 & 2 \\
\hline 9 & 54 & 27.04 & 4 & 12 & 220 & 410 & 4 & 6 \\
\hline 10 & 55 & 22.77 & 1 & 10 & 105 & 10 & 2 & 2 \\
\hline 11 & 53 & 18.44 & 7 & 7 & 145 & 100 & 0 & 0 \\
\hline 12 & 52 & 21.66 & 2 & 16 & 280 & 450 & 2 & 0 \\
\hline 13 & 51 & 26.58 & 1 & 8 & 195 & 50 & 3 & 0 \\
\hline 14 & 50 & 18.75 & 7 & 10 & 222 & 20 & 3 & 0 \\
\hline 15 & 49 & 37.19 & 2 & 12 & 208 & 150 & 2 & 0 \\
\hline 16 & 48 & 24.49 & 4 & 8 & 135 & 180 & 0 & 0 \\
\hline 17 & 48 & 23.28 & 5 & 8 & 135 & 150 & 3 & 0 \\
\hline 18 & 46 & 19.98 & 3 & 8 & 130 & 50 & 2 & 2 \\
\hline 19 & 41 & 24.68 & 10 & 10 & 231 & 50 & 0 & 2 \\
\hline 20 & 48 & 21.15 & 1 & 10 & 190 & 200 & 2 & 3 \\
\hline 21 & 49 & 26.02 & 4 & 20 & 205 & 900 & 2 & 0 \\
\hline 22 & 46 & 21.72 & 6 & 8 & 130 & 55 & 4 & 2 \\
\hline 23 & 47 & 24.50 & 2 & 12 & 142 & 300 & 3 & 0 \\
\hline 24 & 51 & 25.31 & 6 & 10 & 173 & 250 & 3 & 2 \\
\hline 25 & 42 & 25.05 & 1 & 15 & 240 & 100 & 5 & 0 \\
\hline 26 & 32 & 17.48 & 1 & 15 & 75 & 100 & 4 & 0 \\
\hline 27 & 45 & 17.50 & 2 & 13 & 117 & 10 & 2 & 1 \\
\hline 28 & 34 & 25.89 & 7 & 8 & 190 & 500 & 3 & 2 \\
\hline 29 & 38 & 20.39 & 6 & 6.5 & 150 & 250 & 3 & 2 \\
\hline 30 & 44 & 26.64 & 3 & 9 & 155 & 20 & 3 & 0 \\
\hline 31 & 54 & 24.54 & 5 & 10 & 190 & 260 & 3 & 2 \\
\hline Mean & $50.10 \pm 7.79$ & $23.55 \pm 4.36$ & $3.84 \pm 2.45$ & $11.24 \pm 3.27$ & $182.32 \pm 52.39$ & $231.77 \pm 238.90$ & $2.32 \pm 1.60$ & $1.23 \pm 1.43$ \\
\hline
\end{tabular}

*Patient arrived ward after operation; ${ }^{\star \star} 24 \mathrm{~h}$ later after VAS score 1. VAS: visual analogue score

\section{Statistical analysis}

All data were calculated using JMP Pro 15 (SAS Institute Inc.) and Excel (Microsoft Inc.). The relationships of myoma number and size to operation time and blood loss were calculated by one-way ANOVA, with $P$ value $<0.05$ as significant. The control chart of learning curve was calculated by the cumulative sum control chart (CUSUM) method.

\section{RESULTS}

The demographic data of all 31 women are listed in Table 1. The mean age of the patient was $50.10 \pm$ 7.79 years (95\%CI: $47.24-52.95$ years). The mean BMI was $23.55 \pm 4.36 \mathrm{~kg} / \mathrm{m}^{2}$ (95\%CI: $21.95-25.15 \mathrm{~kg} / \mathrm{m}^{2}$ ). The mean number of myoma in single patient was $3.84 \pm 2.45$ (95\%CI: 2.94-4.74). The mean maximum diameter of myoma in single patient was $11.24 \pm 3.27 \mathrm{~cm}$ (95\%CI: 10.04-12.44 cm). The mean operation time was $182.32 \pm 52.39 \mathrm{~min}$ (95\%CI: 163.11-201.54 min). The mean blood loss was $231.77 \pm 238.90 \mathrm{~mL}$ (95\%CI: 144.14-319.40 mL). The Visual Analogue Score (VAS) of pain when immediately arriving at the ward after operation was $2.32 \pm 1.60$ (95\%CI: 1.74-2.91) and dropped to $1.23 \pm 1.43$ (95\%CI: 0.70-1.75) after $24 \mathrm{~h}$.

In Table 2, we describe the position and size of all myomas in all 31 patients in our study. Traditionally, posterior wall intramural myoma is thought to be more difficult to deal with laparoscopically, especially 
Table 2. The position, number and size of myoma uteri of 31 patient (Original data)

\begin{tabular}{|c|c|c|c|c|}
\hline Patient (myoma number) & Intramural & Subserous & Posterior intramural & Broad ligament \\
\hline $1(4)$ & $3(6,2,1)^{\star}$ & $1(15)$ & & \\
\hline $2(6)$ & $3(12,10,8)$ & $3(1,1,1)$ & & \\
\hline $3(1)$ & & $1(16)$ & & \\
\hline $4(1)$ & & & & $1(14)$ \\
\hline $5(3)$ & $1(14)$ & $2(2,1)$ & & \\
\hline $6(3)$ & $1(9)$ & $2(3,2)$ & & \\
\hline $7(8)$ & $2(14,6)$ & $6(3,2,1,1,0.5,0.3)$ & & \\
\hline $8(3)$ & $1(6)$ & $2(10,1)$ & & \\
\hline $9(4)$ & $2(12,8)$ & $2(3,1)$ & & \\
\hline $10(1)$ & $1(10)$ & & & \\
\hline $11(7)$ & $3(10,6,4)$ & $4(3,2,1,0.5)$ & & \\
\hline $12(1)$ & $1(16)$ & & & \\
\hline $13(1)$ & & & & $1(8)$ \\
\hline $14(7)$ & $3(8,6,5)$ & $4(10,8,1,0.5)$ & & \\
\hline $15(2)$ & $1(12)$ & $1(3)$ & & \\
\hline $16(4)$ & $1(3)$ & $2(1,1)$ & $1(8)$ & \\
\hline $17(5)$ & $3(8,7,4)$ & $2(2,0.5)$ & & \\
\hline $18(3)$ & $2(8,6)$ & $1(1)$ & & \\
\hline $19(10)$ & $10(10,4,3,2,1.5,1,1,1,0.5,0.3)$ & & & \\
\hline $20(1)$ & $1(10)$ & & & \\
\hline $21(4)$ & $4(20,5,4,3)$ & & & \\
\hline $22(6)$ & $5(8,4,3,2,1)$ & $1(0.5)$ & & \\
\hline $23(2)$ & $1(12)$ & $1(3)$ & & \\
\hline $24(6)$ & $2(10,4)$ & $4(1,1,1,1)$ & & \\
\hline $25(1)$ & $1(15)$ & & & \\
\hline $26(1)$ & & & $1(15)$ & \\
\hline $27(2)$ & & & $2(13,5)$ & \\
\hline $28(7)$ & $2(8,7)$ & $4(4,2,1,0.5)$ & & $1(5)$ \\
\hline $29(6)$ & $1(6.5)$ & $4(3,2,0.5,0.5)$ & $1(5.5)$ & \\
\hline $30(3)$ & & $2(5,3)$ & & $1(9)$ \\
\hline $31(5)$ & $2(10,5)$ & $3(3,2,1)$ & & \\
\hline Total (average) & $58(6.72 \pm 4.41 \mathrm{~cm})$ & $52(2.58 \pm 3.35 \mathrm{~cm})$ & $5(9.30 \pm 4.49 \mathrm{~cm})$ & $4(3.74 \pm 1.87 \mathrm{~cm})$ \\
\hline
\end{tabular}

${ }^{\star}$ number (size in centimeters)

when there is no uterine manipulator use. We divided them by the intramural type myoma and position. In total, 119 myomas were removed in our study. There were $58(48.74 \%)$ intramural myomas, with mean diameter of $6.72 \pm 4.41 \mathrm{~cm}$ (95\%CI: 5.55-7.89 cm). Fifty-two (43.70\%) subserous type myoma were removed with mean diameter $2.58 \pm 3.35 \mathrm{~cm}(95 \% \mathrm{CI}: 1.65-3.52 \mathrm{~cm})$. Posterior myoma accounted for five $(4.20 \%)$ pieces with mean diameter of $9.30 \pm 4.49 \mathrm{~cm}(95 \% \mathrm{CI}$ : $3.72-14.88 \mathrm{~cm})$. The broad ligament type myoma accounted for four pieces $(3.36 \%)$ and the mean diameter was $3.74 \pm 1.87 \mathrm{~cm}(95 \% \mathrm{CI}: 3.05-14.95 \mathrm{~cm})$.

As shown in Table 3, the number of myomas $>5 \mathrm{~cm}$ in diameter was $51(42.9 \%)$. There were 36 intramural myomas $>5 \mathrm{~cm}$ of $58(62.1 \%)$, with mean diameter of $9.26 \pm 3.46 \mathrm{~cm}(95 \% \mathrm{CI}: 8.09-10.44 \mathrm{~cm})$. The number of subserous type myomas $>5 \mathrm{~cm}$ in diameter was six of $52(11.5 \%)$, with an average size of $10.67 \pm 4.18 \mathrm{~cm}$ (95\%CI: $6.28-15.05 \mathrm{~cm}$ ). There were no changes in the posterior intramural type and broad ligament type myomas.

There were $20(64.52 \%)$ women with more than three myomas in our study [Figure $1 \mathrm{~A}]$. When we deducted all the myoma $<5 \mathrm{~cm}$, there were still $15(48.39 \%)$ women with more than two myomas that were $>5 \mathrm{~cm}$ [Figure 1B]. The distribution of different types of myoma is shown in Figure 1C. Intramural myomas accounted for $48 \%$, subserous myoma accounted for $44 \%$, and posterior intramural myoma and broad ligament myoma accounted for $4 \%$ each. When only myomas $\geq 5 \mathrm{~cm}$ were included, intramural myoma 
Table 3. The position, number and size of myoma uteri of 31 patient (Data of myoma size $\geq \mathbf{5} \mathrm{cm}$ )

\begin{tabular}{|c|c|c|c|c|}
\hline Patient (myoma number) & Intramural & Subserous & Posterior intramural & Broad ligament \\
\hline $1(2)$ & 1(6) & $1(15)$ & & \\
\hline $2(3)$ & $3(12,10,8)$ & & & \\
\hline $3(1)$ & & $1(16)$ & & \\
\hline $4(1)$ & & & & $1(14)$ \\
\hline $5(1)$ & $1(14)$ & & & \\
\hline $6(1)$ & $1(9)$ & & & \\
\hline $7(2)$ & $2(14,6)$ & & & \\
\hline $8(2)$ & $1(6)$ & $1(10)$ & & \\
\hline $9(2)$ & $2(12,8)$ & & & \\
\hline $10(1)$ & $1(10)$ & & & \\
\hline $11(2)$ & $2(10,6)$ & & & \\
\hline $12(1)$ & $1(16)$ & & & \\
\hline $13(1)$ & & & & $1(8)$ \\
\hline $14(5)$ & $3(8,6,5)$ & $2(10,8)$ & & \\
\hline $15(1)$ & $1(12)$ & & & \\
\hline $16(1)$ & & & $1(8)$ & \\
\hline $17(2)$ & $2(8,7)$ & & & \\
\hline $18(2)$ & $2(8,6)$ & & & \\
\hline $19(1)$ & $1(10)$ & & & \\
\hline $20(1)$ & $1(10)$ & & & \\
\hline $21(2)$ & $2(20,5)$ & & & \\
\hline $22(1)$ & $1(8)$ & & & \\
\hline $23(1)$ & $1(12)$ & & & \\
\hline $24(1)$ & $2(10)$ & & & \\
\hline $25(1)$ & $1(15)$ & & & \\
\hline $26(1)$ & & & $1(15)$ & \\
\hline $27(2)$ & & & $2(13,5)$ & \\
\hline $28(3)$ & $2(8,7)$ & & & $1(5)$ \\
\hline $29(2)$ & $1(6.5)$ & & $1(5.5)$ & \\
\hline $30(2)$ & & $1(5)$ & & $1(9)$ \\
\hline $31(2)$ & $2(10,5)$ & & & \\
\hline Total (average) & $36(9.26 \pm 3.46 \mathrm{~cm})$ & $6(10.67 \pm 4.18 \mathrm{~cm})$ & $5(9.30 \pm 4.49 \mathrm{~cm})$ & $4(3.74 \pm 1.87 \mathrm{~cm})$ \\
\hline
\end{tabular}

accounted for $70 \%$, subserous myoma dropped to $12 \%$, posterior intramural myoma accounted for $10 \%$, and broad ligament myoma accounted for $8 \%$ [Figure 1D].

As shown in Figure 2, we analyzed the relationship between the number of myomas and the blood loss, showing no significant relationship. We also calculated the relationship between the maximum diameter of myoma in a patient with the blood loss, showing a significant relationship.

We calculated the relationships between operation time and the number and maximum diameter of myomas. As shown in Figure 3A, there was no significant relationship between operation time and the number of myomas removed. The operation time became longer as the maximum diameter of myoma increased, but this relationship did not reach significance [Figure 3B].

As to the learning curve, we used the CUSUM method to calculate the learning curve by operation time [Figure 4]. No learning curve was noted in our study.

Concerning to perioperative complications, there were three cases $(9.7 \%)$ with blood loss over $500 \mathrm{~mL}$, but all could be corrected after intraoperative blood transfusion without any sequalae. There were three cases (9.7\%) with postoperative fever $>38^{\circ} \mathrm{C}$ and persisted over $48 \mathrm{~h}$. However, all subsided and the patients were discharged after three days of intravenous antibiotics. All 31 patients completed their surgery by single-port laparoscope without changing to multiport laparoscopy or laparotomy. There were no major complications such as bowel, ureter, bladder injuries, or incisional hernia. 
A

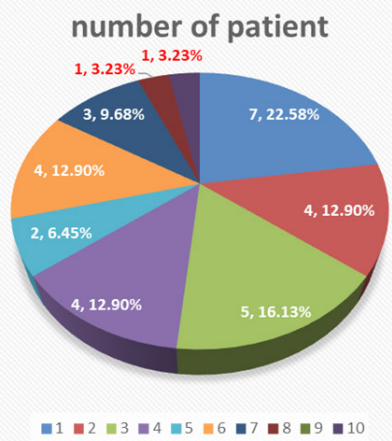

C Distribution of different type myomas

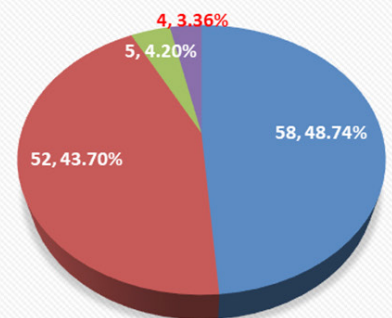

intramural mobserous mosterior mbroad ligment
B

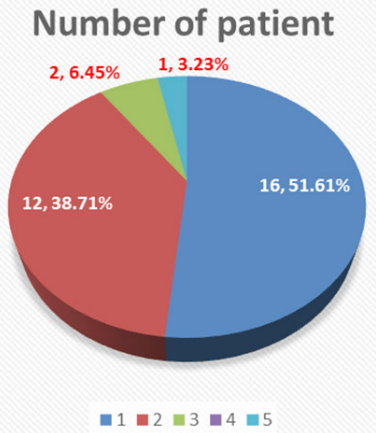

D Distribution of different types myoma $>=5 \mathrm{~cm}$

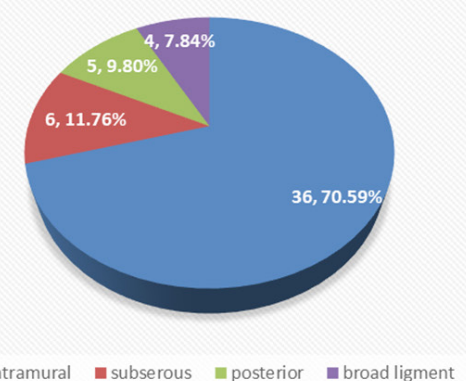

Figure 1. Distribution of relationship of patient and myoma. A: patient number and the myoma number; $\mathrm{B}$ : patient number with myoma $\geq$ $5 \mathrm{~cm}$; C: distribution of myoma; D: distribution of myomas $\geq 5 \mathrm{~cm}$

A

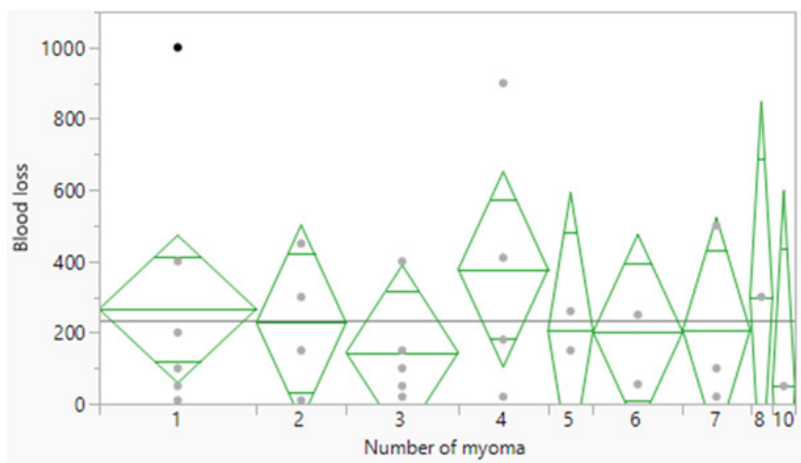

B

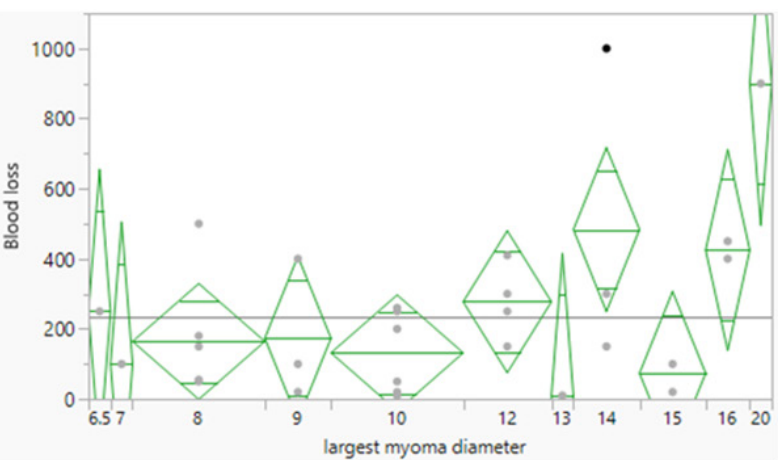

Figure 2. Relationship of blood loss and the number $(\mathrm{A}, P=0.9516)$ and $\max \operatorname{diameter}(\mathrm{B}, P=0.0359)$ of myoma

During the same period, we also had 10 cases of conventional laparoscopic myomectomy (using three trocars) and 10 cases of non-virgin single-port laparoscopic myomectomy (i.e., using uterine manipulator). We compare them in Table 4. The age was younger in those two groups (50.10 \pm 7.79 vs. $42.6 \pm 6.02$ and $42.8 \pm 4.69)$, and the maximum diameter of myoma was smaller in them $(11.24 \pm 3.27 \mathrm{~cm} v s .7 .30 \pm 2.06 \mathrm{~cm}$ and $8.71 \pm 2.05 \mathrm{~cm}$ ). However, in BMI, number of myomas removed, operation time, blood loss, and VAS score when arriving at the ward and $24 \mathrm{~h}$ later, there were no significant differences among the three groups.

We compared our data to previous published literature concerning single-port laparoscopic myomectomy, and the results are shown in Table 5. 
A

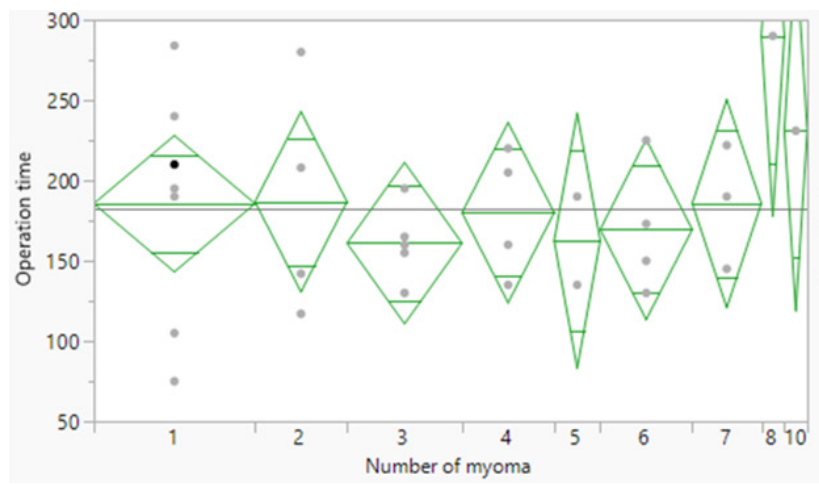

B

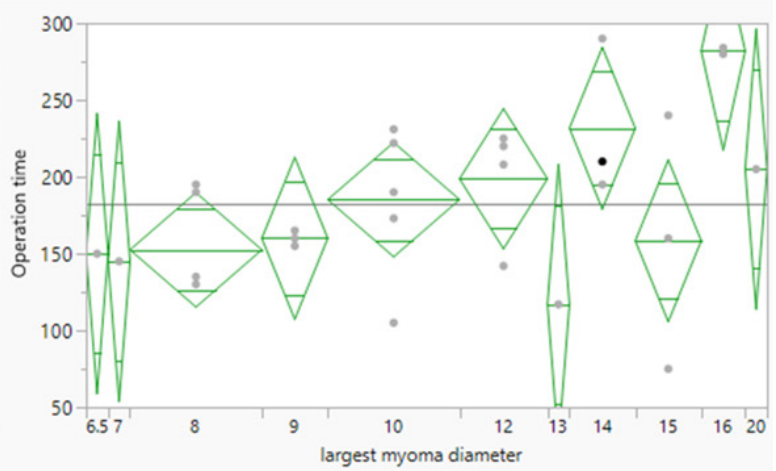

Figure 3. Relationship of operation time with the number $(A, P=0.6378)$ and max diameter of myoma $(B, P=0.0537)$

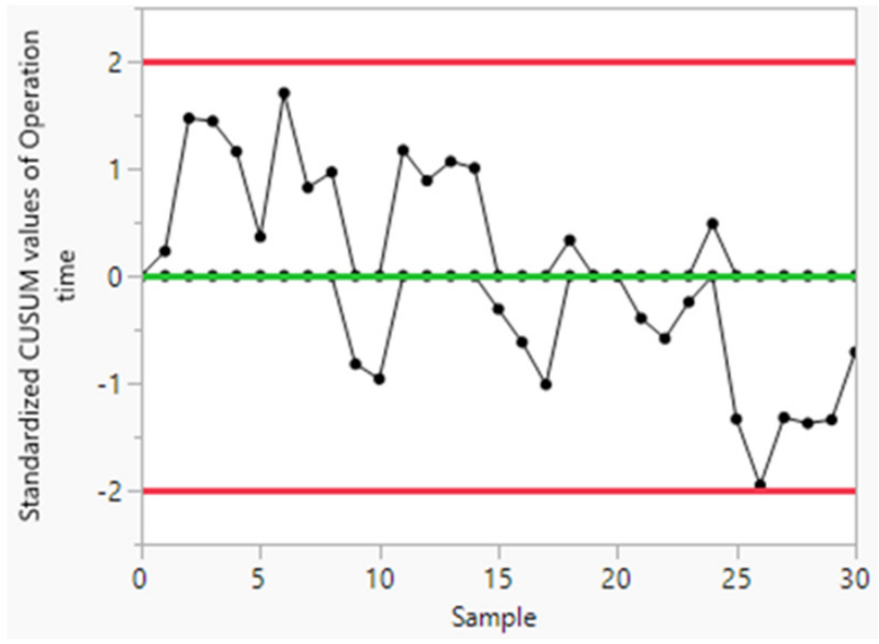

Figure 4. Control chart of operation time. CUSUM: cumulative sum control chart

Table 4. Comparison of single port laparoscopic myomectomy (virgin) group, single port laparoscopic myomectomy (nonvirgin) group and conventional laparoscopic myomectomy group

\begin{tabular}{|c|c|c|c|c|}
\hline & Single port in virgin & Single port in non-virgin & Conventional 3 port & $P$ value \\
\hline Patient number & 31 & 10 & 10 & \\
\hline Age & $50.10 \pm 7.79$ & $42.6 \pm 6.02$ & $42.8 \pm 4.69$ & $0.0025^{\star}$ \\
\hline BMI $\left(\mathrm{kg} / \mathrm{m}^{2}\right)$ & $23.55 \pm 4.36$ & $2.199 \pm 2.90$ & $24.45 \pm 5.21$ & 0.4337 \\
\hline Myoma number & $3.84 \pm 2.45$ & $2.90 \pm 1.73$ & $2.60 \pm 2.01$ & 0.2413 \\
\hline Max diameter of myoma $(\mathrm{cm})$ & $11.24 \pm 3.27$ & $7.30 \pm 2.06$ & $8.71 \pm 2.05$ & $0.0008^{\star}$ \\
\hline Operation time (min) & $182.32 \pm 52.39$ & $152.10 \pm 59.38$ & $173.2 \pm 76.36$ & 0.3759 \\
\hline Blood loss $(\mathrm{mL})$ & $231.77 \pm 238.90$ & $102.50 \pm 146.35$ & $125.00 \pm 206.07$ & 0.1757 \\
\hline VAS score $1^{\star}$ & $2.32 \pm 1.60$ & $1.00 \pm 1.15$ & $2.80 \pm 2.53$ & 0.0586 \\
\hline VAS score $2^{\star \star}$ & $1.23 \pm 1.43$ & $0.20 \pm 0.63$ & $0.80 \pm 1.03$ & 0.0818 \\
\hline
\end{tabular}

*Immediately arrived ward after operation; **24 hours later after VAS score 1. VAS: visual analogue score

\section{DISCUSSION}

Since the introduction of laparoscopic myomectomy in 1979 by Semm ${ }^{[9]}$, numerous studies have been published concerning the feasibility and safety of this minimally invasive method ${ }^{[10-12]}$. When compared to open laparotomy myomectomy, laparoscopic myomectomy remains a safe and effective surgical option with the advantages of a lower drop in hemoglobin ${ }^{[13]}$, less postoperative pain, and faster recovery ${ }^{[14]}$. 
Table 5. Comparison of surgical outcomes with previous published studies ${ }^{[18,19,21-24]}$

\begin{tabular}{lll}
\hline & \multicolumn{1}{c}{ Our studies } & \multicolumn{1}{c}{ Previous published studies } \\
\hline Mean number of myoma & $3.84 \pm 2.45$ & $1-3$ to $1-5$ \\
Mean diameter of max myoma $(\mathrm{cm})$ & $11.24 \pm 3.27$ & $7-14$ \\
Operation time $(\mathrm{min})$ & $182.32 \pm 52.39$ & $77.5 \pm 37.8$ to $191.4 \pm 103.0$ \\
Blood loss $(\mathrm{mL})$ & $231.77 \pm 238.90$ & $114.2 \pm 157.0$ to $224.6 \pm 320.9$ \\
VAS score & $2.32 \pm 1.06^{\star}$ & $1.60 \pm 1.30$ to $3.50 \pm 0.8$ \\
& $1.23 \pm 1.43^{\star \star}$ & \\
\hline
\end{tabular}

*Immediately arrive ward after operation; ${ }^{\star \star} 24$ hours later. VAS: visual analogue score

Concerning the obstetric outcome, both groups show no significant differences in pregnancy rate, abortion rate, and preterm delivery rate ${ }^{[14]}$.

Recently, technological innovations (such as a multichannel single port, articulating instruments, and high-definition laparoscopes) have allowed laparoscopic surgeons to perform gynecologic surgery through only one small incision over the abdomen (single-port laparoscopic surgery) with the aim of further reducing the invasiveness of conventional laparoscopy. There are many reports applying this new method to gynecologic surgeries such as hysterectomy, adnexal surgery, or even cancer surgery ${ }^{[15-17]}$. Its use in myomectomy is limited to advanced laparoscopic surgeons due to the difficulty of multiple suturing and tying $^{[7]}$. However, there are more and more reports on the feasibility and safety of this difficult method ${ }^{[18-22]}$.

In a systematic review and meta-analysis comparing single-port laparoscopic myomectomy with conventional laparoscopic myomectomy published in 2019, Kim et al. ${ }^{[19]}$ concluded that single-port laparoscopic myomectomy is comparable to conventional laparoscopic myomectomy in terms of safety and feasibility and more advantageous in terms of immediate postoperative pain. However, virginity is not mentioned in the literature they included. To the best of our knowledge, this is the first study reporting on the use of single-port laparoscopic myomectomy in virgins.

As is known, it is more difficult in laparoscopic gynecologic surgery to not use a uterine manipulator, especially in myomectomy, which needs the uterine manipulator to change the position of the uterus for proper surgical plane when dissecting myoma and suturing the uterine wall defect.

In our study, the mean number of myoma in a single patient was $3.84 \pm 2.45$, which is comparable to previous studies ${ }^{[18,19,21-25]}$, which range from $1-5$. However, in one patient in our study, 10 myomas were removed in the same operation, which we believe is the most reported in the literature in a single-port laparoscopic myomectomy. The mean diameter of maximum myoma in single patient was 7-14 cm in those studies, and in our study was $11.24 \pm 3.27 \mathrm{~cm}$. The maximum diameter of single myoma removed in our study was $20 \mathrm{~cm}$, which we believe is the largest diameter of myoma removed by single-port laparoscopic surgery reported in the literature. The mean operation time in our study was $182.32 \pm 52.39 \mathrm{~min}$, which is also comparable to those studies (from $77.5 \pm 37.8 \mathrm{~min}$ to $191.4 \pm 103.0 \mathrm{~min}$ ). The mean blood loss was $231.77 \pm 238.90 \mathrm{~mL}$ in our study. The mean blood loss in previous studies ranges from $114.2 \pm 157.0 \mathrm{~mL}$ to $224.6 \pm 320.9 \mathrm{~mL}$. However, there were two extreme values in our study, while the median value of blood loss was $150 \mathrm{~mL}$. We believe the blood loss is comparable to those previous studies. The VAS score in our study was $2.32 \pm 1.06$ when patients arrived at the ward after operation and $1.23 \pm 1.4324 \mathrm{~h}$ later, which is also comparable to those studies (from $1.60 \pm 1.30$ to $3.50 \pm 0.8$ ).

In total, 119 myoma were removed in our study, with $51(42.86 \%)$ being $>5 \mathrm{~cm}$ in diameter. All the posterior intramural and broad ligament type myomas were $>5 \mathrm{~cm}$. Overall, 36 of $58(62.1 \%)$ intramural myomas were $>5 \mathrm{~cm}$. Most subserous type myomas were small; only 15 of $52(28.8 \%)$ were $>5 \mathrm{~cm}$. These results are similar to the reference values. 


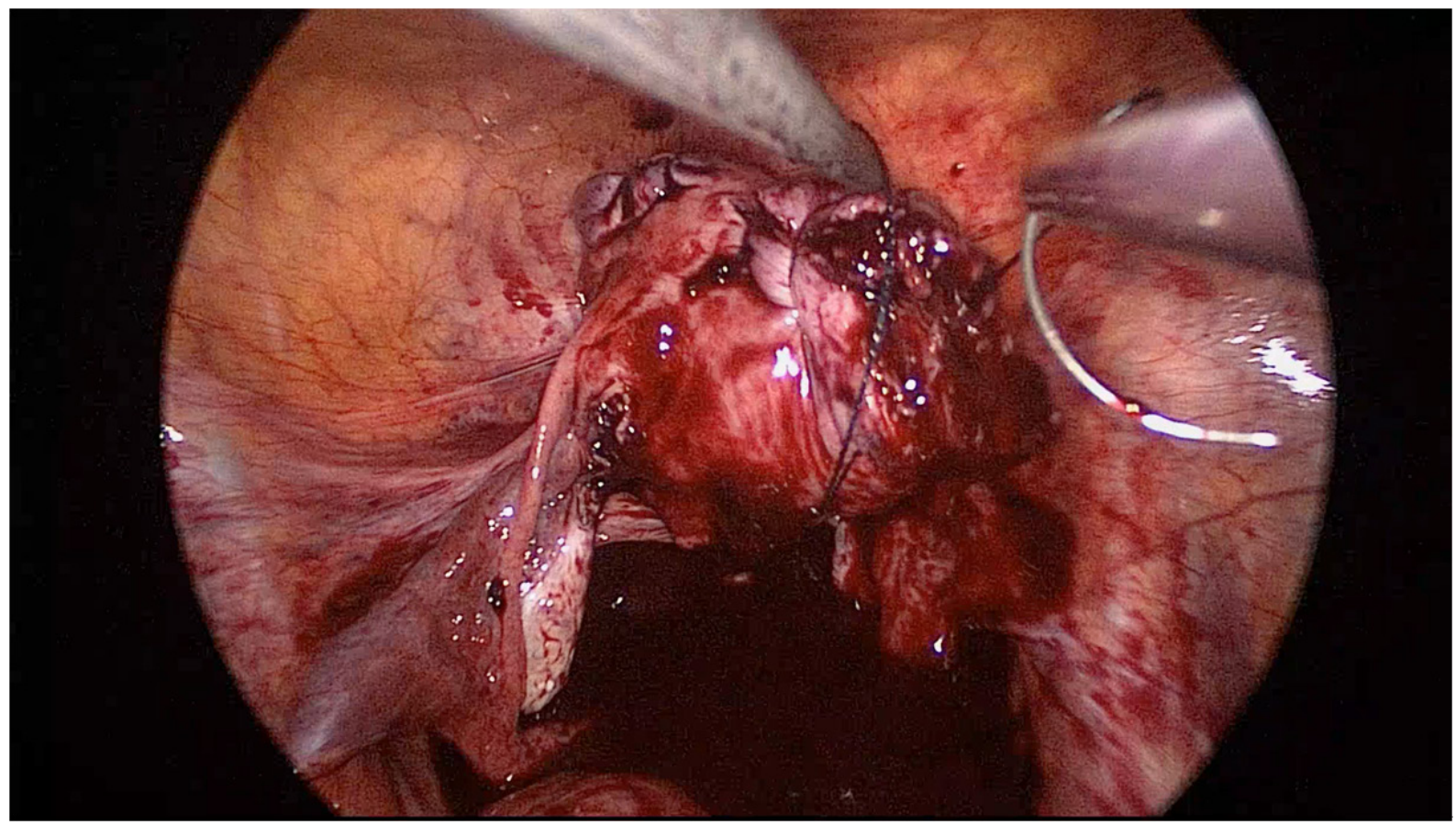

Figure 5. Traction of uterus by holding suture string near uterine wall defect

Traditionally, it is thought that intramural type myoma, especially positioned in posterior uterine wall, is more difficult to remove laparoscopically. It needs elevation of the uterus by uterine manipulator to reveal the myoma. Besides, it is difficult in suture the posterior uterine wall defect in a relatively small space (posterior cul-de-sac). In our study, we did not use uterine manipulator to preserve the patient's virginity. We elevated the uterus by one apparatus and used barbed suture. Then, we could manipulate the uterus by holding the string near the uterine defect [Figure 5]. The benefit of this method is that we could correctly suture on the right plane and angle one at a time.

The relationship of blood loss to the number of myoma removed was insignificant. It might be due to the subserous myoma accounting for a substantial portion of the multiple-myoma patients. However, we did not find any description of the relationship between myoma number and blood loss in the literature. The blood loss was higher when the maximum diameter of myoma was larger. This is reasonable because the greater is the size of the myoma, the narrower is the space in the operation field, which may make it difficult to control bleeding by apparatus when it occurs.

There was no significant relationship between operation time and the myoma number removed. We think it is for the same reason: a substantial portion of multiple myomas was subserous type, which could be removed without difficulty. The operation time was longer when the maximum diameter of myoma became greater, but did not reach significance. We think it is reasonable that removing large myoma is time consuming whether during excision, suturing defect, or removing from the umbilical incision by cold knife blade.

There was no learning curve according to the CUSUM analysis in our study. It may be because the operator is experienced and already familiar with single-port laparoscopic surgery. For those not familiar with single-port laparoscopic surgery, a learning curve may exist to overcome the technical difficulty ${ }^{[26]}$. However, Torng et al. ${ }^{[27]}$ concluded that a learning curve is not required for laparoendoscopic single site surgery for experienced laparoscopic surgeons. 
There is scant literature on the topic of laparoscopic gynecology surgery in virgins. Most of the reports are for diagnostic purposes ${ }^{[28]}$ or case studies on adnexal surgery ${ }^{[29-35]}$. There is one case report on performing a posterior colpotomy laparoscopically to remove a prolapsed myoma in a virgin's vagina ${ }^{[35]}$ to preserve her virginity. However, this is done by multiport laparoscope. There is a retrospective study of 297 cases of laparoscopic-assisted vaginal hysterectomy in virgins and nulliparas using Biswas uterine vaginal elevator $^{[36]}$, but the elevator should be removed laparoscopically after uterus is excised completely. It is not suitable in laparoscopic myomectomy because colpotomy is not necessary. Furthermore, this research is done by multiport laparoscopy.

For virgins with symptomatic myoma, medical treatment can be used. Ulipristal acetate can achieve amenorrhea state sooner than placebo ${ }^{[37]}$ and improves quality of $l i f \mathrm{e}^{[38]}$. In some research, it is used preoperatively, but the benefit is inconclusive ${ }^{[39]}$. However, there are sporadic cases of liver injuries and hepatic failure reported, and its use should be restricted to those whose liver condition is healthy, and periodic liver monitoring before, during, and after treatment is suggested ${ }^{[40]}$. The long-term effect of ulipristal acetate on pregnancy still lacks high quality data. Besides, for patient with large myoma, the mass effect does not disappear with its use. Thus, surgery is needed in these patients.

Uterine artery embolization (UAE) is another choice for those group. According to the 10-year outcomes of the randomized EMMY (Embolization vs. Hysterectomy) trial, about two thirds of hysterectomies can be avoided and health-related quality of life remains comparatively stable. However, $35 \%$ of patients need secondary hysterectomy after $\mathrm{UAE}^{[41]}$. Furthermore, the pregnancy rate was found to be lower and miscarriage rate higher after UAE than after myomectomy ${ }^{[42]}$.

High intensity focused ultrasound is a newer method for treating myoma. The response rate ranges $40 \%$ $85 \%$ in different modalities and studies ${ }^{[43]}$. However, it is expensive in Taiwan, and the mass shrinks slowly. The long-term effect of high intensity focused ultrasound treatment is still not clearly known for myoma.

Surgery is the only way to remove mass and improve symptoms, especially mass-induced ones. The specimen can be obtained by pathologic examination.

The limitation of this study is that it was a retrospective chart review. Further large-scale randomized research is needed to compare with other methods to clarify its limitations and safety.

In conclusion, this is the first report on single-port laparoscopic myomectomy on the virgin womb. In our 31 consecutive cases, the operation time, blood loss, and postoperative VAS score were all comparable to the previous published literature. Without using uterine manipulator, we could still complete the operation successfully without major complications. The manipulation of the uterus could be achieved by myoma screw or suture string when needed. It is feasible for virgin women with symptomatic myoma to receive single-port laparoscopic myomectomy.

\section{DECLARATIONS}

\section{Authors' contributions}

The author contributed solely to the article.

\section{Availability of data and materials}

Not applicable.

\section{Financial support and sponsorship}

None. 


\section{Conflicts of interest}

The author declared that there are no conflicts of interest.

\section{Ethical approval and consent to participate}

Not applicable.

\section{Consent for publication}

Not applicable.

\section{Copyright}

(c) The Author(s) 2020.

\section{REFERENCES}

1. Stewart EA, Cookson CL, Gandolfo RA, Schulze-Rath R. Epidemiology of uterine fibroids: a systematic review. BJOG 2017;124:1501-12.

2. Zimmermann A, Bernuit D, Gerlinger C, Schaefers M, Geppert K. Prevalence, symptoms and management of uterine fibroids: an international internet-based survey of 21,746 women. BMC Womens Health 2012;12:6.

3. Ekin M, Cengiz H, Öztürk E, Kaya C, Yasar L, et al. Genitourinary symptoms and their effects on quality of life in women with uterine myomas. Int Urogynecol J 2014;25:807-10.

4. Fibroids - Treatment. Available from: https:/www.nhs.uk/conditions/fibroids/treatment/ [Last accessed on 17 Mar 2020]

5. Adamson GD. Treatment of uterine fibroids: current findings with gonadotropin-releasing hormone agonists. Am J Obstet Gynecol 1992;166:746-51.

6. Garnock-Jones KP, Duggan ST. Ulipristal acetate: a review in symptomatic uterine fibroids. Drugs 2017;77:1665-75.

7. Song T, Kim TJ, Lee SH, Kim TH, Kim WY. Laparoendoscopic single-site myomectomy compared with conventional laparoscopic myomectomy: a multicenter, randomized, controlled trial. Fertil Steril 2015;104:1325-31.

8. Song T, Cho J, Kim TJ, Kim IR, Hahm TS, et al. Cosmetic outcomes of laparoendoscopic single-site hysterectomy compared with multiport surgery: randomized controlled trial. J Minim Invasive Gynecol 2013;20:460-7.

9. Semm K. New methods of pelviscopy (gynecologic laparoscopy) for myomectomy, ovariectomy, tubectomy and adnectomy. Endoscopy 1979;11:85-93.

10. Dubuisson J, Fauconnier A, Babaki-Fard K, Chapron C. Laparoscopic myomectomy: a current view. Hum Reprod Update 2000;6:588-94.

11. Koh C, Janik G. Laparoscopic myomectomy: the current status. Curr Opin Obstet Gynecol 2003;15:295-301.

12. Takeuchi H, Kuwatsuru R. The indications, surgical techniques, and limitations of laparoscopic myomectomy. JSLS 2003;7:89-95.

13. Seracchioli R, Rossi S, Govoni F, Rossi E, Venturoli S, et al. Fertility and obstetric outcome after laparoscopic myomectomy of large myomata: a randomized comparison with abdominal myomectomy. Hum Reprod 2000;15:2663-8.

14. Chittawar PB, Kamath MS. Review of nonsurgical/minimally invasive treatments and open myomectomy for uterine fibroids. Curr Opin Obstet Gynecol 2015;27:391-7.

15. Park JY, Kim TJ, Kang HJ, Lee YY, Choi CH, et al. Laparoendoscopic single site (LESS) surgery in benign gynecology: perioperative and late complications of 515 cases. Eur J Obstet Gynecol Reprod Biol 2013;167:215-8.

16. Song T, Cho J, Kim TJ, Kim IR, Hahm TS, et al. Cosmetic outcomes of laparoendoscopic single-site hysterectomy compared with multiport surgery: randomized controlled trial. J Minim Invasive Gynecol 2013;20:460-7.

17. Fagotti A, Boruta DM, Scambia G, Fanfani F, Paglia A, et al. First 100 early endometrial cancer cases treated with laparoendoscopic single-site surgery: a multicentric retrospective study. Am J Obstet Gynecol 2012;206:353.e1-6.

18. Kim SM, Baek JM, Park EK, Jeung IC, Choi JH, et al. A comparison of single-, two- and three-port laparoscopic myomectomy. JSLS. 2015;19:e2015.00084.

19. Kim JY, Kim KH, Choi JS, Lee JH. A prospective matched case-control study of laparoendoscopic single-site vs conventional laparoscopic myomectomy. J Minim Invasive Gynecol 2014;21:1036-40.

20. Lee D, Lee JR, Suh CS, Kim SH. A systematic review and meta-analysis comparing single port laparoscopic myomectomy with conventional laparoscopic myomectomy. Eur J Obstet Gynecol Reprod Biol 2019;239:52-59.

21. Lee D, Kim SK, Kim K, Lee JR, Suh CS, et al. Advantages of single-port laparoscopic myomectomy compared with conventional laparoscopic myomectomy: a randomized controlled study. J Minim Invasive Gynecol 2018;25:124-32.

22. Kim SK, Lee JH, Lee JR, Suh CS, Kim SH. Laparoendoscopic single-site myomectomy versus conventional laparoscopic myomectomy: a comparison of surgical outcomes. J Minim Invasive Gynecol 2014;21:775-81.

23. Choi CH, Kim TH, Kim SH, Choi JK, Park JY, et al. Surgical outcomes of a new approach to laparoscopic myomectomy: single-port and modified suture technique. J Minim Invasive Gynecol 2014;21:580-5.

24. Lee SW, Park EK, Lee SJ, Lee KH. Comparison study of consecutive 100 cases of single port vs. multiport laparoscopic myomectomy; technical point of view. J Obstet Gynaecol 2017;37:616-21.

25. Han CM, Lee CL, Su H, Wu PJ, Wang CJ, et al. Single-port laparoscopic myomectomy: initial operative experience and comparative outcome. Arch Gynecol Obstet 2013;287:295-300. 
26. Lee HJ, Kim JY, Kim SK, Lee JR, Suh CS, et al. Learning curve analysis and surgical outcomes of single-port laparoscopic myomectomy. J Minim Invasive Gynecol 2015;22:607-11.

27. Torng PL, Lin KH, Hwang JS, Liu HS, Chen IH, et al. Learning curve for laparoendoscopic single-site surgery for an experienced laparoscopic surgeon. Gynecol Minim Invasive Ther 2013;2:126-31.

28. Kielly M, Jamieson MA. Pelvic inflammatory disease in virginal adolescent females without tubo-ovarian abscess. J Pediatr Adolesc Gynecol 2014;27:e5-7.

29. Hornemann A, von Koschitzky H, Bohlmann MK, Hornung D, Diedrich K, et al. Isolated pyosalpinx in a 13-year-old virgin. Fertil Steril 2009;91:2732.e9-10.

30. Li PC, Chen BC, Yeh BH, Kao SP, Ding DC. Hydrosalpinx with adnexa torsion treated with a salpingostomy in a virgin woman. Gynecol Minim Invasive Ther 2018;7:136-8.

31. Pinkert M, Klein Z, Tepper R, Beyth Y. Hydrosalpinx with adnexal torsion in an adolescent virgin patient--a diagnostic dilemma: case report and review of the literature. J Pediatr Adolesc Gynecol 2006;19:297-9.

32. Rottenstreich M, Smorgick N, Pansky M, Vaknin Z. Isolated torsion of accessory fallopian tube in a young adolescent. J Pediatr Adolesc Gynecol 2016;29:e57-8.

33. Sabry M, Ait Allah AS, Roshdy E, Al-Hendy A. Laparoscopic management of a large torted ovarian cyst in an adolescent virgin: a case report. Int J Womens Health 2012;4:223-5.

34. Wehbe GS, Doughane M, Bitar R, Sleiman Z. Laparoscopic posterior colpotomy for a cervico-vaginal leiomyoma: hymen conservative technique. Facts Views Vis Obgyn 2016;8:169-71.

35. Zaat TR, Braakhekke MWM, Kaaijk EM, Peters LW. Quadruple torsion of the fallopian tube in an 18-year-old virgin: a rare twist. BMJ Case Rep 2018;2018:bcr2018224671.

36. Wong WS, Lee TC, Lim CE. A retrospective study of laparoscopic-assisted vaginal hysterectomy (LAVH) in virgins and nulliparae. Eur J Obstet Gynecol Reprod Biol 2011;157:217-21.

37. Liu JH, Soper D, Lukes A, Gee P, Kimble T, et al. Ulipristal Acetate for Treatment of Uterine Leiomyomas: A Randomized Controlled Trial. Obstet Gynecol 2018;132:1241-51.

38. Lukes AS, Soper D, Harrington A, Sniukiene V, Mo Y, et al. Health-related quality of life with ulipristal acetate for treatment of uterine leiomyomas: a randomized controlled trial. Obstet Gynecol 2019;133:869-78.

39. Ferrero S, Vellone VG, Barra F, Scala C. Ulipristal acetate before hysteroscopic and laparoscopic surgery for uterine myomas: help or hindrance? Gynecol Obstet Invest 2019;84:313-25.

40. Donnez J, Arriagada P, Marciniak M, Larrey D. Liver safety parameters of ulipristal acetate for the treatment of uterine fibroids: a comprehensive review of the clinical development program. Expert Opin Drug Saf 2018;17:1225-32.

41. de Bruijn AM, Ankum WM, Reekers JA, Birnie E, van der Kooij SM, et al. Uterine artery embolization vs hysterectomy in the treatment of symptomatic uterine fibroids: 10-year outcomes from the randomized EMMY trial. Am J Obstet Gynecol 2016;215:745.e1-e12.

42. Karlsen K, Hrobjartsson A, Korsholm M, Mogensen O, Humaidan P, et al. Fertility after uterine artery embolization of fibroids: a systematic review. Arch Gynecol Obstet 2018;297:13-25.

43. Cheung VYT. High-intensity focused ultrasound therapy. Best Pract Res Clin Obstet Gynaecol 2018;46:74-83. 